\title{
Time-Driven Activity Based Costing for the Improvement of IT Service Operations
}

\author{
Adenle A. Adeoti ${ }^{1} \&$ Raul Valverde ${ }^{2}$ \\ ${ }^{1}$ Galaxy Backbone plc, Abuja, Nigeria \\ 2 John Molson of School of Business, Concordia University, Canada \\ Correspondence: Raul Valverde, John Molson School of Business, Concordia University, Montreal, QC., H3G \\ 1M8, Canada. Tel: 44-514-848-2424 ext.2968. E-mail: rvalverde@jmsb.concordia.ca
}

Received: October 8, 2013

Accepted: November 20, 2013

Online Published: December 15, 2013

doi:10.5539/ijbm.v9n1p109

URL: http://dx.doi.org/10.5539/ijbm.v9n1p109

\begin{abstract}
This study aims to show that application of Time-Driven Activity Based Costing (TDABC) to the management of cost of Information Technology (IT) Services operations and how it can be used to achieve significant cost reduction. To achieve this; a case study organization was used and the scope of activities was limited to Technical Services department Operations units. Interviews were conducted with the unit managers and their operations staff. These units are the Network Operations Centre, Data Centre, Service Desk and Field Services units. These units provide support to existing services and satisfy requests that involve modification of these services. From the interview, a list of services were developed and linked to activities and time to execute each was provided by the operational staff. Time equations were developed from the activity groups that supported each type of service. Capacity cost rates were derived per unit by obtaining a ratio of the monthly cost of running each unit and the practical time resource capacity of each unit. A TDABC model was then simulated with Microsoft Excel; which incorporated the activities, the time to deliver each and the capacity cost rate to derive the cost of delivering a service. Data for six months of service request, incident and change orders were obtained to simulate a test scenario. The result of the test showed that two variations (out of six) of that incident type cost more than $75 \%$ of the overall cost of that incident type, though they constitute about $30 \%$ of the incident type. This study showed that TDABC is an effective tool in identification of costly processes which may then allow IT operations managers and supervisors to take critical decisions about cost control, charge-back or costing of services.
\end{abstract}

Keywords: TDABC, cost reduction, internet services, cost accounting, time driven systems

\section{Introduction}

\subsection{Introduce the Problem}

This study will be looking at some of the activity cost factors in provision of Internet services. Activity Based Costing $(\mathrm{ABC})$ is a costing technique where employee activities are linked to resource consumed and then to cost objects like services (or products) and customers so that the cost of delivery can be identified or attributed per customer or service. $\mathrm{ABC}$ is a business performance measurement framework that is used in conjunction with other business processes to determine cost of services or products (Kellen \& Wolf, 2003). The traditional $\mathrm{ABC}$ method was found to be difficult to implement and maintain due to the need to obtain information by interview (which is usually subjective), model a large number of activities and link them to cost objects. TDABC was introduced to simplify the process by using time to derive the capacity cost rate in such a manner as to obtain estimates of the cost per unit time; which is derived by dividing the total cost of supplied capacity (over an accounting period) by the practical (effective) capacity of the resources used within the period.

The study will focus on the determination of cost due to each service type and the efforts to support such services. Other cost elements like bandwidth, storage and CPU utilization can easily be determined for each customer or service type, but our focus for this study will be on the services staff activity contributions to services only. This is because we want to show that the overhead due to staff activities can be accounted for by using the TDABC method of cost accounting. 
TDABC will be used to determine the cost of activities that the support staff carries out to deliver services to customers. This allows calculation of cost for each service type or project; and with historic data of customer support activities (use of the helpdesk, service requests and administrative support) the cost of servicing each customer over a period of time can be determined. The ability to do this will allow the business to make decisions about service options and customers' profitability. It will also help to show if there are redundancies within some service units that can be redistributed to improve efficiency or reduce cost of outsourcing. This study's main objective will be to show that TDABC can be used to fill the costing void that is common with most service organizations (especially IT services organizations) that find it difficult to justify spending and produce budget figures.

\section{Literature Review}

Service quality is a critical success factor for most service providers because this factor determines the customer satisfaction, it is also very important to be able to determine cost as accurately as possible (Peebles, et al., 2001). This is what Activity Based Costing (ABC) allows businesses to be able to do. There has been a lot of work done in analyzing the effectiveness of Activity Based Costing (ABC) and Time-Driven Activity Based Costing (TDABC) in improving the visibility of cost within organizations. Many have praised ABC (and its other variants like TDABC) and many have also criticized it for difficulty of implementation and accuracy of the models developed. Neumann, Gerlach and Moldauer (2004) supports ABC for being an improvement over the traditional method of costing IT services; which tend to relate the costs to the allocated resources or facility (CPUs, storage and network facilities). In contrast, $\mathrm{ABC}$ allocates the cost due to each customer or service based on the activities that supports such a customer or service in relation to the portion on the resources used. Meanwhile, LaLonde B. and Pholen, T. (1996) noted the inadequacy of ABC for supply chain costing; they pointed out that $\mathrm{ABC}$ is internally focused and therefore does not account for upstream and downstream elements of the supply chain that are out of the control of the producing organization.

$\mathrm{TDABC}$ has been applied more to factory environment and product manufacturing than for service oriented environments where no tangible output is produced. The cost of activities that contribute to providing a product and the use of facilities are usually considered as overhead in traditional accounting methods. ABC techniques have been able to enable accounting of the activity cost that contribute to the production of good or service. Kaplan and Anderson (2007) identified the following issues with ABC when applied to medium sized organizations; especially when there are small changes to the operations or they want to obtain regular monthly reports from the model:

- The interviewing and surveying process was time-consuming and costly.

- The data for the $\mathrm{ABC}$ model were subjective and difficult to validate.

- The data were expensive to store, process, and report.

- Most $\mathrm{ABC}$ models were local and did not provide an integrated view of enterprise wide profitability opportunities.

- The ABC model could not be easily updated to accommodate changing circumstances.

- The model was theoretically incorrect when it ignored the potential for unused capacity.

These issue lead to many companies abandoning their ABC models (Szychta, 2010) or not adopting the ABC model at all. These issues lead Kaplan and Anderson to proposing TDABC, which was straight forward and easy to implement and maintain compared to $\mathrm{ABC}$.

Activity Based Costing (ABC) and Time-Driven Activity Based Costing (TDABC) are principles of accounting for resource allocation that help organizations have better cost visibility. Implementation of ABC or TDABC can have a major impact on how work is viewed and done within an organization; this can lead major changes in operational procedures and product costing. A lot of organizations underestimate the impact of these techniques on their organization. The problem usually arises from staff perception of change and natural resistance to change exhibited by all human; it is also important to take into consideration the culture of the organization regarding change management (Huczynski \& Buchanan, 2006).

Reyhanoğlu (2004), found that out of a study group of organizations that started ABC implementation, only about $10 \%$ were successful. Operational services employees will want to show that they have used their time or resources to the full capacity, thereby saying that there is no redundancy. Managers on the other hand will like to show that $A B C$ does not contribute significantly to operational cost efficiency. Sanford (2009) found that by comparing several $\mathrm{ABC}$ and non- $\mathrm{ABC}$ companies, it cannot be conclusively said the $\mathrm{ABC}$ companies performed 
better. It shows that implementing $\mathrm{ABC}$ alone is not enough, it is important that it be followed up with practices that will bring about delivering value to the organization. The key to success is to ensure that as much as there is management buy-in, there is a requirement that all the staff have a clear idea about the objectives of the project. They should be made to see the benefits for the organization and eventually for individual staff.

By late nineties, $\mathrm{ABC}$ has been in use in a lot of organizations, both in government and private industries. This was mainly because of its ability to reveal hidden sources of cost and highlight profitability; over time, ABC was being used for capacity planning and predictive modeling (Turney, 2008). ABC adoption should be based on good cost management techniques where it will be made robust by ensuring that it (Neumann, Gerlach and Moldauer, 2004);

- $\quad$ Should add value;

- Identify unique cost drivers for each activity;

- Should ensure that cost management activities are linked to cost drivers.

It is also important that $\mathrm{ABC}$ model accounts for redundant resources (time, space or any other resource measures) so that the cost per unit time (or resource) can be accurately measured. Traditional ABC has the problem of not accounting accurately for redundant resources because it typically uses the ratio of resource used on per activity bases, but TDABC is able to overcome this by using the method aggregation of time (or resource) used per activity (Kaplan \& Anderson, 2007).

Since this project will be looking at methods of reducing IT services activity cost, we will be considering the use of TDABC for cost assignment to cost objects and then look at how cost may be reduced by modification of activity or staffing structure. Similar work was done by Neumann, Gerlach and Moldauer (2004) by using cost assignment techniques with the aim of developing an $\mathrm{ABC}$ costing model that will assist in chargeback and process improvement. The model was successful partly because they had tried to make it as simple as possible to avoid the issue of complexity in development and update of the model. Szycha (2010) pointed out that TDABC is able to achieve a higher complexity and better accuracy when applied to large service oriented organization than $\mathrm{ABC}$, because TDABC uses time as the primary cost driver and time equations to account for variations in activities. Examples of such variations may include being a first time request, expedited request, special packaging, or quantity requests and so on. TDABC is able to directly assign cost to objects (transactions, processes, order types or customers) compared to the $\mathrm{ABC}$ method of assigning costs to resources first before assignment to objects, which is a more complex.

\subsection{TDBAC Benefits}

Traditional accounting methods usually determine overhead costs by dividing cost across products based on estimated ratio of resources like machine time or space occupied. This can be a problem when the production output is intangible, like services. The overheads allocated are usually not accurate (Cokins, 2001), which usually lead to wrong estimates of costs. The problem of cost allocation was resolved with the introduction of Activity Based Costing (ABC).

$\mathrm{ABC}$ allows companies to properly allocate overhead costs to products and services by measuring more accurately the resource consumption in manufacturing products or providing services. This measurement is done by listing the activities that a service organization performs to deliver services and then dividing the total time over these activities. The advantage of $\mathrm{ABC}$ over traditional methods is that there is more accurate measure of cost associated with each cost object, which enable better decision making while determining pricing or reducing operational costs. The major disadvantage of $\mathrm{ABC}$ has been the amount of data that require processing when updating the model or when there are changes to the operating processes.

TDABC was developed by Robert Kaplan and Steven Anderson to solve the problems of complexity and need for high volume of data processing that was encountered by many organizations when using ABC (Gilbert, 2007). TDABC allows companies to have better cost visibility across customer groups (or customers), service types (or products) and service operation processes. By being able to create cost profiles for different customer types, they will be able to determine profitability based on customer types. Some customer types may be found not to be quite profitable based on their needs. This will allow the company to consider a change in how these customers are engaged which will eventually lead to better services and profitability. Secondly, better visibility of cost of products or services offering will allow the supplier organization to better decide on price and services to retire, make or outsource to more efficient or specialized companies. Thirdly, by being able to determine the costs of operational processes, organizations will be able to optimize for lower cost of operations.

Another benefit of TDABC is that it is able to provide information about redundant resources. This will allow 
managers to determine how to increase output by utilizing these redundant capacities to improve efficiency where there is a need for more resources (Kaplan \& Anderson, 2007). ABC also allows managers to improve their budgeting capabilities (TDABC will allow this as well) by being able to accurately determine the resource requirement to meet specific company objectives; overheads are correctly allocated to cost objects (Cokins, 2001).

Implementation of TDABC has been successful in a lot of manufacturing and services company (Kaplan \& Anderson, 2007). The scope of application and degree of success may vary due to the degree of preparedness and involvement of the management and staff of the case study organizations.

A key tool that most authors have mentioned when using companies as case study organizations is an Enterprise Resource Planning (ERP) application. Gilbert (2007) quoted Kaplan as confirming that the implementation of TDABC was made possible with the use of ERP data from companies that he has worked with to set up such TDABC costing systems. This application is useful because it keeps track of activities and use of resources across the entire organization. The information within the system can then be used to derive useful information about the cost profile of cost objects like customers.

For IT organizations it is also important that there are properly defined processes and workflows to ensure that activities are standardized and are repeatable. This will ensure that activity times that will be used to model the TDABC would be standard and not subject to individuals' method of performing such activity. A common used and adopted IT management framework is ITIL, which undergoes constant review for improvement (ITIL, 2011).

\subsection{TDBAC Approach}

Cost management before Activity Based Costing (ABC) has not been efficient at allocation of overhead and indirect costs to different cost objects (customers, products or processes) because of the usual practice of accountants averaging out the overhead costs. Turney (2008) discussed how $\mathrm{ABC}$ can be used to forecast transaction level of activities so that resource requirements can also be forecasted to meet new business targets. $\mathrm{ABC}$ has been able to bring the idea of cost allocation based on the required resource to produce or support a cost object; this is usually referred to as Activity-Based Management (ABM). ABM is based on the fact that costs or spending come from activities performed to deliver products or services (Kren, 2008).

TDABC simplifies the process of creating an activity-based costing model; this has made it easy to create models that do not need very high levels of details and accuracy and still is able to have a reasonable working model. The ABC model can be started at a high level of abstraction of the activities and then drilled down as the needs require (Kaplan \& Anderson, 2007), the study done by Bamber and Hughes (2001) also showed that this approach was adopted by the implementation team. Starting with too much details tend to create a large complex model that will affect the acceptability by users of the system (or decision makers) and will increase the cost of maintenance.

Kaplan and Anderson (2007) recommended that organizations can use TDABC for cost management by performing what-if analysis and Activity-Based Budgeting (ABB). What-if analysis is done using historical data to forecast performance or cost of services or products based on demand or company sales projections. When this analysis is done using the techniques of $\mathrm{ABC}$ (somewhat in reverse) to determine (or budget) for the resource requirements, it can be referred to as Activity-Based Budgeting. These processes allow companies to adjust the supply of resources to the demands of cost objects. Companies will be able to do this by using a current TDABC model of their operational costs to forecast resource requirements to meet future requirements after considerations on how to optimize their processes and adjust the product pricing, product and customer mix to increase profitability.

TDABC uses time as a measure of resource consumption by activities that have been triggered by cost objects to produce outputs. These activities may vary based on the service or product request, the type of customer, location of delivery and several other factors. The time to complete any activity and its variations is treated as an additive factor, therefore representing them as additive linear equation is sufficient (Kaplan \& Anderson, 2007).

Time equations in TDABC are a representative of the services offering of a department or unit. They can be used to predict resource requirements to meet future business requirements or carry out what-if analysis required for budgeting purposes. If service delivery and product manufacturing has been broken down into activities and sub-activities (that accounts for variations in the services or products due to factors like customizations, volume demand, or destination of delivery), then time equations can be written for them directly. The base activity is the regarded as the activity to produce the standard service or product and time variations are added to this based on 
the variations introduced by custom orders and delivery types. Kaplan and Anderson (2003) stated time equation in the a generalized formula as shown below;

$$
T_{\beta}=\beta_{0}+\beta_{1} X_{1}+\ldots+\beta_{n} X_{n}
$$

Where:

$\mathrm{T}_{\beta}-$ the time needed to perform activity $\beta$,

$\beta_{0}$ - standard time for performing the basic activity, e.g. 15 minutes,

$\beta_{i}-$ the estimated time for the incremental activity $i,(i=1, \ldots, n)$, e.g. $\beta_{1}=3$ minutes,

$X_{i}-$ the quantity of incremental activity $i,(i=1, \ldots, n)$, e.g. number of line items.

The above equation is of the form $\mathrm{y}=\mathrm{a}+\mathrm{bx}$; where $\mathrm{y}$ is the dependent variable and $\mathrm{x}$ is the independent variable; $\mathrm{a}$ and $\mathrm{b}$ are the intercept and slope respectively. Therefore the time equation can be viewed as a form of linear Regression equation. On our case, there can be more than one independent variable in a time equation. To simplify calculations, all independent variable should be fixed except the one being compared to the dependent variable (the time to perform the activity in equation).

Time equations are the first requirement in creation of the TDABC model; the time obtained per cost objects (based on activities requirements to satisfy the demand of the cost object) is applied to the cost rate for the department or unit that provides the service or product to obtain the cost. The second requirement is the capacity cost rate, discussed in the next sub-section.

Capacity cost rate is the ratio of the departmental or unit cost (numerator) to the practical capacity (denominator) of the department or unit; this cost rate is used to derive the cost of orders, products and customers. The departmental cost consists of the total employee compensation, occupancy, technology and corporate support. The practical capacity is the available resource that can be applied to performing an activity after deductions due to inherent constraints have been done (Kaplan \& Anderson, 2007).

The departmental cost consist of several cost elements like salaries of employees (with other benefits like medical insurance, pension and taxes), indirect labor costs that supervises or performs support functions (like human resources and administration), equipment and technology, occupancy (or rent) and other indirect costs from support departments like finance, human resources and administration. All these cost elements can be estimated with some level of accuracy by getting historical information from the accounts department for the period in review. There are components that cannot be estimated easily but if the factors that contribute to these cost elements are carefully considered, good estimates can be obtained. For instance, the number of employees in a department can be the determining cost factor for finance and administrative support cost.

The practical capacity is the capacity that can be effectively used out of the total capacity that can be put to work. This capacity can be estimated arbitrarily by choosing an estimated fraction (say 0.8 or 0.85 ) or theoretically by deducting known resource fraction that is typically not put to use (Kaplan \& Anderson, 2007). In the case of TDABC, time is the primary resource, so what will be deducted are times for break, training and meetings.

To develop time equations and assign resource consumption to each cost objects; a list of operational activities needs to be developed that will capture all activities done to provide the services or products (cost objects like customer orders). To develop this list, the services that a department offers should be listed and then broken down into sub-services and then to activities and any variations of these activities. The time determined to carry out these activities has some tolerance and the model will not be too affected (Cokins, 2001); however, the time can be verified by directly measuring the time it takes to perform an activity a few times and an average can be determined.

\section{Case Study}

The case study organization is an IT services organization that provides Internet and connectivity based services to its customers. These services include the followings (at a high level);

- Internet Protocol (IP) Connectivity Services;

- Hosted Services;

- $\quad$ Support Services.

All these services are provided by the Technical Services Department which is divided into four units or groups. These groups provide several IT services to meet the requirements of the business services. The groups are as follows; 
- $\quad$ Network Operations Centre (NOC);

- Data Centre (DC);

- $\quad$ Service Desk (SD);

- $\quad$ Field Services (FS).

There are other groups that provide other kinds of service that support the organization's business growth and handover to the groups listed above (which I will like to refer to as primary service groups); these groups source from the primary groups as required to perform services that cannot be attributed to any particular business service or customer (such as network design, security evaluation, product development and testing). Two of such groups are the Project and Security groups; they are constituted when required. At the interview stage, these temporary or occasional activities have been captured by asking questions around the activities that the members of the permanent groups perform (even though these are not directly linked to any IT services the group performs for a customer.

To satisfy customer requests or resolve service issues, the Technical Services department has put in place processes that define workflows for satisfaction of these requests.

Figure 1 below shows a schematic of information flow within the units to satisfy customer service requests and support as obtained from the initial interview with the Technical Services department unit managers. This shows that the Service Desk unit is the central unit for customer interactions with the Technical Services department. Most of the incidents are resolved at the Helpdesk (a sub-unit of Service Desk) and those requiring specialist attention are channeled to the appropriate unit. For requests, information requests are handled by the Helpdesk and service change or additions are escalated to the appropriate Technical Services unit.

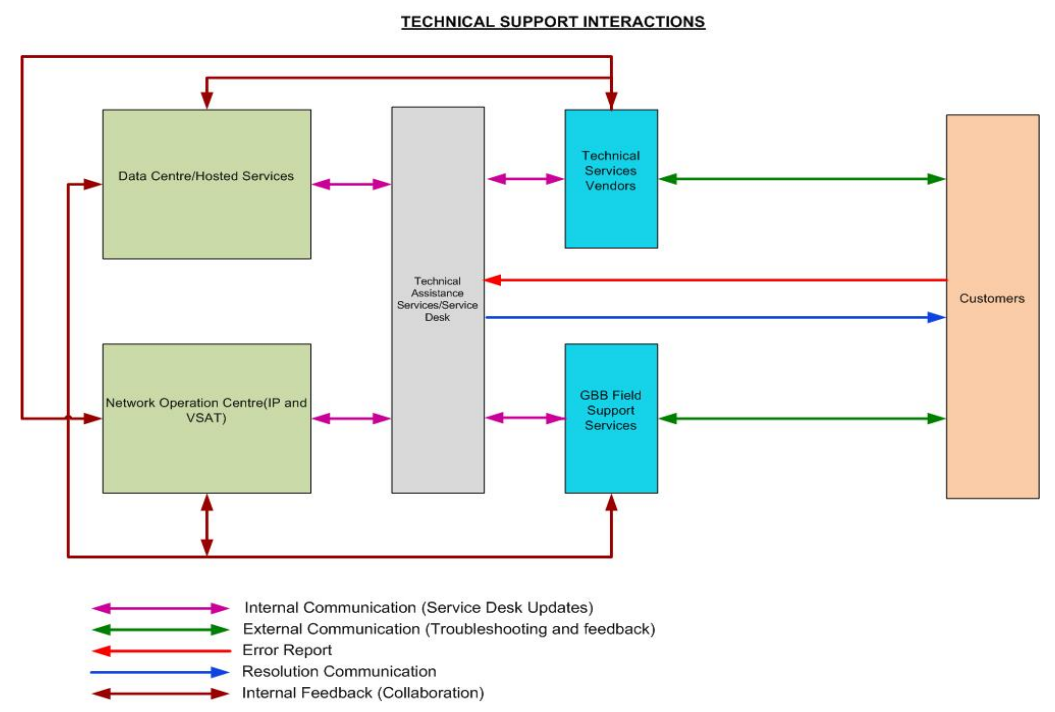

Figure 1. Technical services units communications

To arrive at a list of activities the approach used was to look at the business services, and map them to the IT services performed by each Technical Services group. It was these IT Services list that was used to derive the activities list; however, by asking the interviewees to further consider their work schedules, other activities that do not directly support any particular customer but support business processes were derived.

Table 1 below shows a list of IT services provided by the Technical Services department of the case study organization; it shows a mapping of the business services and corresponding IT services that support them. This table was derived from the interviews with the managers of the Technical Services units. This mapping was taken further by listing all activities used to provide each of these IT services. 
Table 1. Mapping of business to IT services

\begin{tabular}{|c|c|c|}
\hline & Business Services & IT Services \\
\hline \multirow{6}{*}{1} & \multirow{6}{*}{ Internet Protocol Connectivity Services } & Site Provisioning \\
\hline & & Site Commissioning \\
\hline & & VSAT Support \\
\hline & & Fibre Support \\
\hline & & Radio Support \\
\hline & & Site Survey \\
\hline \multirow{7}{*}{2} & \multirow{7}{*}{ Hosted Services } & Database management \\
\hline & & Storage \\
\hline & & Virtualization \\
\hline & & Backup \\
\hline & & Server Hosting \\
\hline & & Co-location \\
\hline & & Hosted Services \\
\hline \multirow{14}{*}{3} & \multirow{14}{*}{ Support Services } & Level 2 Support \\
\hline & & Level 3 Support \\
\hline & & Hub Infrastructure Management \\
\hline & & Satellite Space Segment Management \\
\hline & & Capacity Management \\
\hline & & Monitoring and Reporting \\
\hline & & Maintenance and Support \\
\hline & & Helpdesk Services \\
\hline & & Incident Management \\
\hline & & Change Management \\
\hline & & Process and Service review \\
\hline & & LAN Support \\
\hline & & Third party Support Management \\
\hline & & Power Systems Support \\
\hline \multirow{8}{*}{4} & \multirow{8}{*}{ Other Services } & Research and Development \\
\hline & & NOC Operations \\
\hline & & POC Support \\
\hline & & Setup Studio \\
\hline & & Access Management \\
\hline & & Power and Cooling \\
\hline & & Enterprise Applications (on-premise) \\
\hline & & Third Party Support Management \\
\hline
\end{tabular}

Time equations are representations of the variations in activity times due to difference in the characteristics of the same activity, similar activities or closely related activities (that go together). The time measures used in this study are in minutes for uniformity. To determine the time intervals, service engineers or operations staff and their managers provided the time estimates for each activity type. Where there are discrepancies between time estimates, the manager determines which time estimate to use or a few instances of the activities were observed. The approach that is adopted for this project is to develop a time equation for each IT service as shown in the IT Services column of Table 1 above.

As an example to show how time equations were calculated, we will consider the first service in the NOC services, Site Provisioning. This service is Site Provisioning which is provided to prepare for the addition of a new customer on the network to satisfy the business service of Internet Protocol (IP) Connectivity Service. The service requires information about the medium of connection and the customer's proposed bandwidth. Other required variation for setting up can be the need to configure a Public IP address, setup some routing or Network Address Translation (NAT) configuration on the access network routers. All these information comes from the customer service requirements and designed solution (a business service unit called "Solutions Design" unit provides the solutions document).

Site Provisioning service consists of the following activities: 
- $\quad$ Planning - To determine the resource requirement that will be used on the back-end infrastructure to satisfy the customer's service type.

- $\quad$ Planning with IP request - Where public IP addresses will be required to meet the customer's business needs

- Configuration and bandwidth allocation - This activity is where the IP parameters and requested bandwidth are configured on the core routers and the bandwidth manager.

- Configuration and bandwidth allocation with routing-This is a variation of the above activity with a need to set up special routing rules.

- Configuration and bandwidth allocation with Network Address Translation (NAT)-NAT is a variation of routing but some customer requires both routing and NAT setup to achieve their business needs.

The time equation for this service is shown below, taking time information from the NOC activity list.

Site Provisioning time $(\min )=5\{$ Plan $\}+10\{$ if with IP $\}+15\{$ Bandwidth allocation $\}+10\{$ Routing $\}+10\{$ NAT $\}$

The chart below (Figure 2) shows the linear nature of the time equation above; the chart shows the slopes due to each of the independent variables above for a sample of 10 sites. Three of the variables (with IP, Routing and NAT) have the same slope, therefore are lying on each other. For a full list of time equations representing all the IT services provided by the Technical Services department, see Appendix.

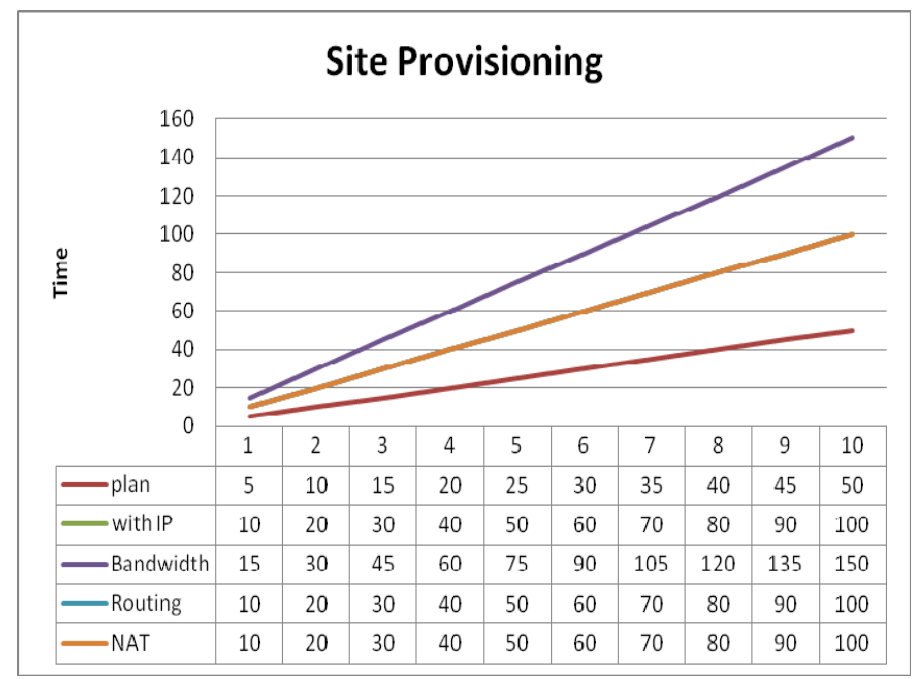

Figure 2. Site provisioning time equation regression plots

To determine the cost of the each Technical Service unit capacity, information about the spending done by the case study organization of each of these units were obtained from the Accounts department. The information requested was in the scope listed below.

- $\quad$ Staff remunerations and any over-head (like tax, pension and insurance);

- $\quad$ Rent and facility maintenance(attributable to NOC, DC and the Technical Services office facility);

- Indirect costs due to these units for Admin, HR and finance support.

For each service unit, the table below shows the cost in dollars on monthly basis the sum of the cost of salaries (including benefits, tax and insurance), facility and administrative overheads. The figures in the table were derived from the case study organization's 2011 Accounting Records; the figures are monthly average of the spending over the period of ten months, January to October 2011. 
Table 2. Monthly cost per unit

\begin{tabular}{llllll}
\hline & NOC & Data Centre & Service Desk & Field Service & TOTAL \\
\hline Staff & 11 & 8 & 11 & 12 & $\mathbf{4 2}$ \\
Cost (in Dollars) & $60,645.16$ & $37,903.23$ & $22,741.94$ & $30,322.58$ & $\mathbf{1 5 1 , 6 1 2 . 9}$ \\
Percent & $37 \%$ & $23 \%$ & $16 \%$ & $24 \%$ & $\mathbf{1 0 0 \%}$ \\
\hline
\end{tabular}

To obtain the capacity cost per Service unit, both the practical capacity estimates per unit (estimated on weekly basis) and the monthly cost per unit will be brought to the same duration. To bring both figures to monthly estimates we will multiply the weekly estimated practical capacity for the units that work every day of the week by;

(Days in a year $/($ months $\mathrm{x}$ weekly working days $)=365 /(12 \times 7)=4.34$

For Service Desk unit that works only 5 working days in a week:

$($ Days in a year $-($ Weekend days + public holidays $)) /($ months $x$ weekly working days $)=(365-(104+12)) /(12$ $\mathrm{x} 5)=4.15$

Therefore NOC Capacity cost $=$ Total monthly cost $/$ NOC Practical Capacity $=60,645.16 /(22,752 \times 4.34)=$ $\$ 0.61 /$ minute

Data Centre Capacity cost $=$ Total monthly cost $/$ Data Centre Practical Capacity $=37,903.23 /(16,992 \times 4.34)=$ $\$ 0.51$ minute

Service Desk Capacity cost $=$ Total monthly cost $/$ Service Desk Practical Capacity $=22,741.94 /(21,120 \times 4.15)=$ $\$ 0.26 /$ minute

Field Services Capacity cost $=$ Total monthly cost $/$ Field Service Practical Capacity $=30,322.58 /(23,616 \times 4.34)$ $=\$ 0.30 /$ minute

The capacity cost rates above reflects some of the practical realities on ground; the NOC and Data Centre have higher cost rate because of higher facility costs. They both occupy large spaces that require cooling and utility power consumption. Contrasting these two units to Service Desk and Field Service teams, show that these teams cost about $50 \%$ less.

\section{Methods}

The approached used was to interview the unit managers and the operators to obtain services provided by each unit to both internal (business and other Technical Services units) and externally to the customers. The questions were asked in an iterative manner (Yin, 2009); this was used to gradually break down the services to functions and then to activities. To start the session the following questions served as guidance to obtain the information required:

What are the services you offer to the business?

What are the tasks that constitute the delivery of these services?

How long does each service task take to complete?

The interview was done with the operators only, the Unit Manager preferred to have the inputs from the operators and these were reviewed by him. This approach was adopted to obtain the activity list and time to perform the activities for the all Technical Services units (Network Operations Centre, Data Centre, Field Services and Service Desk). All time estimates are included in tables 5, 6, 7 and 8 in the appendix.

The TDABC model will be created to evaluate the costs of each service type and this will be used to obtain information about the cost of servicing sample customers of each service type in the case study organization. This kind of information will be useful for guiding decisions about process optimization, where non-value adding activities can be eliminated to save time and reduce cost.

To achieve the creation of the TDABC model, Microsoft Excel will be used to program the time equations and the value of each Technical Services units' Capacity Cost Rates. From business operations records, it is possible to draw up a list of service activities that has been performed as a result of demands from cost objects like customer service requests or support services requirements. Figure 3 below shows a screen shot of the Worksheet developed to generate the cost for the NOC activities. We were able to derive five time equations for NOC activities which were categorized into two general groups; Customers service and Business services. The 
screen shot shows the column "Total Time" and "Cost" which displays the total time calculated by each time equation and the cost (after multiplying with the NOC Capacity Cost rate) respectively. Using this table, it is possible to generate the cost of any service that the NOC delivers. However, most Customer services span more than one Technical Services unit.

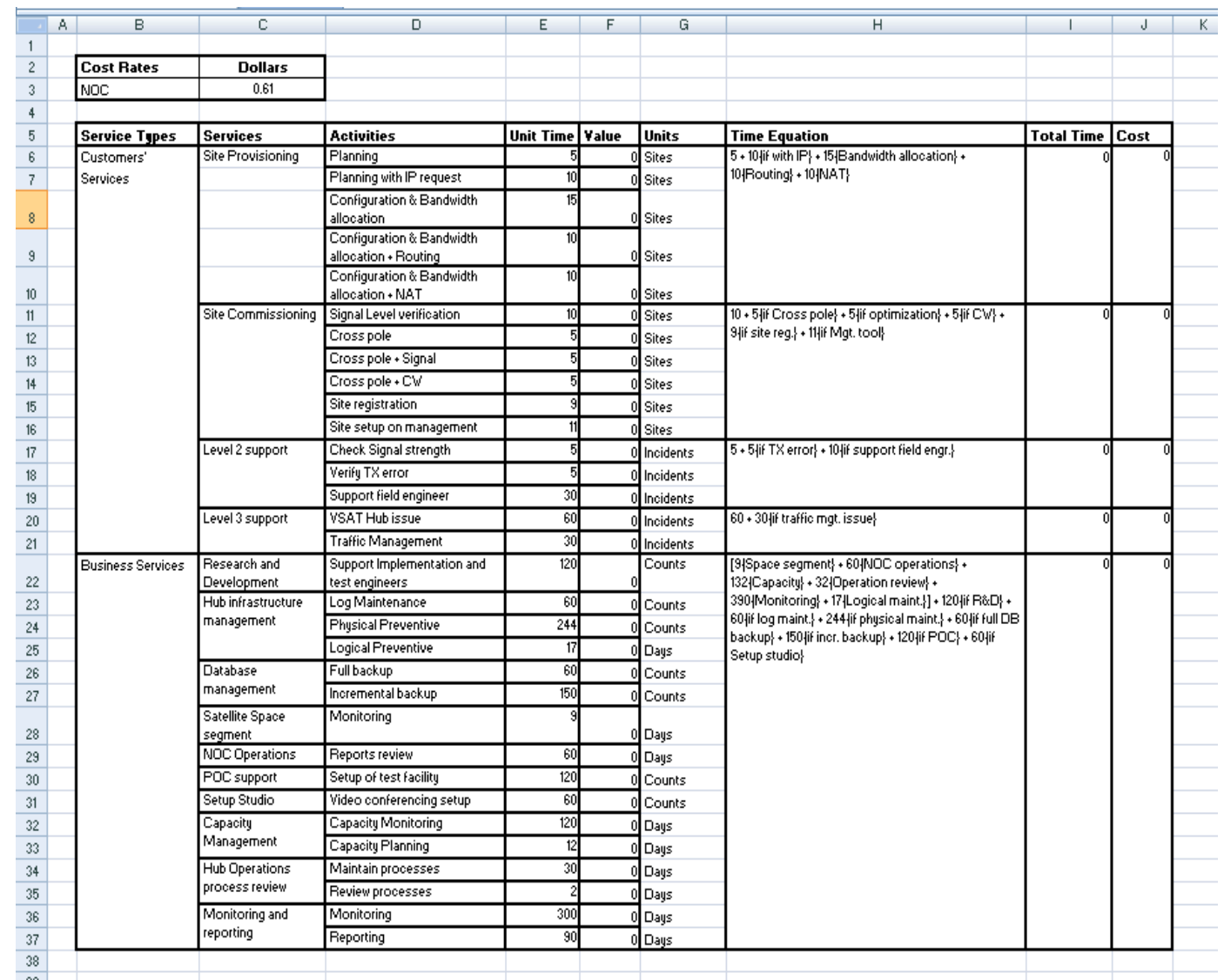

Figure 3. NOC activities cost sheet

To obtain the data for this test, we will be looking at the available Service Management application within the case study organization. This application is CA (Computer Associates Technologies) Service Desk Manager for IT service management. It contains several modules that are used to manage IT processes like Incident Management, Change Management and Request Management. The application keeps a record of all incidents, requests and changes which are what translates to activities in each of the Services units we have been discussing. All service requests, incidents and change requests are logged into the system for tracking and accountability.

The CA Service Desk application allows the export of data to Microsoft Excel where it can be formatted to obtain information about categories and volume of incident or request based on customers. This information can now be used to derive the cost of each service type or cost of servicing a customer over a period of time. The data used in this study is for a 6 months period (27 June to 27 December 2011).

The exported data will be sorted by several group characteristics to be able to derive useful information.

1) By Service Groups - to obtain cost information on the activities by each Technical Services unit.

2) By Incident/Request/Change type - to obtain cost information about the Support processes.

The table and figure below show the distribution of Incidents, Requests and Change orders based on fault assignment to Service units.

\section{Results}

The table and figure below show the distribution of Incidents, Requests and Change orders based on fault 
assignment to Service units.

Table 3. Six months service order distribution

\begin{tabular}{llll}
\hline Technical Unit & Incident Volume & Request Volume & Change Volume \\
\hline NOC & 162 & 97 & 47 \\
Data Centre & 148 & 481 & 34 \\
Service Desk & 1043 & 7 & 0 \\
Field Support & 1802 & 64 & 2 \\
& $\mathbf{3 1 5 5}$ & $\mathbf{6 4 9}$ & $\mathbf{8 3}$ \\
\hline
\end{tabular}

For the breakdown of Incidents and Requests into areas (or types) see table 3. It shows that the VSAT related incidents are more than $30 \%$, followed by LAN related incidents. The VSAT incidents are within the Field Services team most time consuming incidents to fix (mainly because each time a site is visited; there it the high likelihood of antenna realignment; this activity also consumes time from the NOC team). Further interviews and deeper reviews of the VSAT incidents with the Field Service team showed that about $50 \%$ of these incidents did not required site visits, $30 \%$ required antenna alignment and the rest just required equipment replacement. For the LAN issues (where the organization offers Managed LAN services), most incidents were LAN cable replacement for end users or within the cable trunks.

To test the TDABC model we have developed, we will use the VSAT incident category which has been identified will bring the most cost savings to the organization because it has the highest volume. To start work on this, we will take further look at the types VSAT incidents and derive their different variations and then get the list of activities required to resolve them

For VSAT incidents, there are four possible variations; the percentages of these variations shown in brackets were obtained by analyzing the details of the incidents;

- VSAT incidents resolved by the Service Desk (estimated as 50\%).

- VSAT incidents escalated by Service Desk to the NOC team and resolved by the NOC team (estimated as $5 \%)$.

- $\quad$ VSAT incidents escalated by Service Desk to the NOC for further checks and then transferred to the Field Service team for site visit and resolution.

○ Resolution was done without NOC support (like part replacement; estimated at 7\%).

- Resolution was done requiring NOC Support (estimated at 13\%).

- $\quad$ VSAT incidents escalated by Service Desk to the Field Service team for visit and resolution.

- Resolution was done without NOC support (like part replacement; estimated as 8\%).

- Resolution was done requiring NOC Support (estimated as 17\%).

Variation 1: VSAT incidents resolved by the Service Desk;

Helpdesk services (from Service Desk time equations, shown in the Appendix, Table 13) time equation will provide all required parameters.

$1\{$ if Call receipt $\}+4\{$ if logging $\}+10\{$ if troubleshoot $\}+3$ nnew user detail $\}+2\{$ if update existing user $\}+5\{$ if survey $\}+5\{$ if Close $\}=1\{1\}+4\{1\}+10\{1\}+3\{0\}+2\{0\}+5\{0\}+5\{1\}=20$ Minutes

Cost $=$ Service Desk Capacity cost rate $x$ Time spent $=\$ 0.26 \times 20=\$ 5.20$ per incident.

Variation 2: VSAT incidents escalated by Service Desk to the NOC team and resolved;

The time equation for the Helpdesk Services (Service Desk time equations) and the Level 2 Support (NOC time equations, Appendix, Table 9) are the required set of activities to complete this task. For the Helpdesk services, the example above applies; therefore we only have to calculate for the NOC's Level 2 support service,

$5+5\{$ if TX error $\}+10\{$ if support field engr. $\}=5\{1\}+5\{1\}+30\{1\}=40$ Minutes

Therefore Cost $=$ Helpdesk Service cost $+($ Level 2 support time $\mathrm{x}$ NOC Capacity cost rate $)=\$ 5.20+(40 \mathrm{x}$ $\$ 0.61)=\$ 29.60$ per incident. 
Variation 3a: VSAT incidents escalated by Service Desk to the NOC and then transferred to the Field Service team for visit and resolution (without NOC support);

The required time equations are those for Service Desk's Helpdesk services (from Service Desk time equations, see Appendix, Table 13), NOC's Level 2 support (from NOC time equations, see Appendix, Table 9) and Field Services' VSAT support (from Field Services time equations, see Appendix, Table 15); therefore total time is:

$[1\{$ if Call receipt $\}+4\{$ if logging $\}+10\{$ if troubleshoot $\}+3$ new user detail $\}+2$ \{if update existing user $\}+$ $5\{$ if survey $\}+5\{$ if Close $\}]+[5+5\{$ if TX error $\}+30\{$ if support field engr. $\}]+[960\{$ if installation $\}+180\{$ if alignment $\}+60\{$ if replacement $\}+30\{$ if wireless $\}]$

$=[1\{1\}+4\{1\}+10\{1\}+3\{0\}+2\{0\}+5\{0\}+5\{1\}]+[5\{1\}+5\{1\}+30\{0\}]+[960\{0\}+180\{0\}+60\{1\}+$ $30\{0\}]=20$ (Service Desk minutes) +10 (NOC minutes) +60 (Field Services minutes)

Total cost $=(20 \times \$ 0.26)+(10 \times \$ 0.61)+(60 \times \$ 0.30)=\$ 29.30$ per incident.

Variation 3b: VSAT incidents escalated by Service Desk to the NOC and then transferred to the Field Service team for visit and resolution (with NOC support);

The required time equations are those for Service Desk's Helpdesk services (from Service Desk time equations, see Appendix , Table 13), NOC's Level 2 support (from NOC time equations, see Appendix, Table 9) and Field Services' VSAT support (from Field Services time equations, see Appendix, Table 15); therefore total time is:

$[1\{$ if Call receipt $\}+4\{$ if logging $\}+10\{$ if troubleshoot $\}+3\{$ new user detail $\}+2$ if update existing user $\}+$ $5\{$ if survey $\}+5\{$ if Close $\}]+[5+5\{$ if TX error $\}+30$ \{if support field engr. $\}]+[960\{$ if installation $\}+180\{$ if alignment $\}+60\{$ if replacement $\}+30\{$ if wireless $\}]$

$=[1\{1\}+4\{1\}+10\{1\}+3\{0\}+2\{0\}+5\{0\}+5\{1\}]+[5\{1\}+5\{1\}+30\{1\}]+[960\{0\}+180\{1\}+60\{0\}+$ $30\{0\}]=20$ (Service Desk minutes) +20 (NOC minutes) +180 (Field Services minutes)

Total cost $=(20 \times \$ 0.26)+(40 \times \$ 0.61)+(180 \times \$ 0.30)=\$ 83.60$ per incident.

Variation 4a: VSAT incidents escalated by Service Desk to the Field Service team for visit and resolution (without NOC support);

The required time equations are those for Service Desk's Helpdesk services (from Service Desk time equations, see Appendix, Table 15) and Field Services' VSAT support (from Field Services time equations, see Appendix, Table 15); therefore total time is:

$[1\{$ if Call receipt $\}+4\{$ if logging $\}+10\{$ if troubleshoot $\}+3\{$ new user detail $\}+2\{$ if update existing user $\}+$ $5\{$ if survey $\}+5\{$ if Close $\}]+[960\{$ if installation $\}+180\{$ if alignment $\}+60\{$ if replacement $\}+30\{$ if wireless $\}]$

$=[1\{1\}+4\{1\}+10\{1\}+3\{0\}+2\{0\}+5\{0\}+5\{1\}]+[960\{0\}+180\{0\}+60\{1\}+30\{0\}]=20$ (Service Desk minutes) +60 (Field Service minutes)

Total cost $=(20 \times \$ 0.26)+(60 \times \$ 0.30)=\$ 23.20$ per incident .

Variation $4 \mathrm{~b}$ : VSAT incidents escalated by Service Desk to the Field Service team for visit and resolution (with NOC support);

The required time equations are those for Service Desk's Helpdesk services (from Service Desk time equations, see Appendix, Table 13), NOC's Level 2 support (from NOC time equations, see Appendix, Table 9) and Field Services' VSAT support (from Field Services time equations, see Appendix, Table 15); therefore total time is:

$[1$ if Call receipt $\}+4\{$ if logging $\}+10\{$ if troubleshoot $\}+3$ new user detail $\}+2$ if update existing user $\}+$ $5\{$ if survey $\}+5\{$ if Close $\}]+[5+5\{$ if TX error $\}+30\{$ if support field engr. $\}]+[960$ \{if installation $\}+180\{$ if alignment $\}+60\{$ if replacement $\}+30\{$ if wireless $\}]$

$[1\{1\}+4\{1\}+10\{1\}+3\{0\}+2\{0\}+5\{0\}+5\{1\}]+[5\{0\}+5\{0\}+30\{1\}]+[960\{0\}+180\{1\}+60\{0\}+$ $30\{0\}]=20$ (Service Desk minutes) +30 (NOC minutes) +180 (Field Services minutes)

Total cost $=(20 \times \$ 0.26)+(30 \times \$ 0.61)+(180 \times \$ 0.30)=\$ 77.50$ per incident.

Using information obtained about the VSAT incidents, we derived the table below: 
Table 4. Support cost for VSAT incidents over 6 months

\begin{tabular}{lllll}
\hline & & Unit Cost (\$) & Incident Volume & Total Cost (\$) \\
\hline 1 & Variation 1 & 5.20 & 574 & $2,984.80$ \\
2 & Variation 2 & 29.60 & 56 & $1,657.60$ \\
3 & Variation 3a & 29.30 & 81 & $2,373.30$ \\
4 & Variation 3b & 83.60 & 150 & $12,540.00$ \\
5 & Variation 4a & 23.20 & 92 & 2.134 .40 \\
6 & Variation 4b & 77.50 & 196 & $15,190.00$ \\
TOTAL & & $\mathbf{1 , 1 4 9}$ & $\mathbf{3 6 , 8 8 0 . 1 0}$ \\
\hline
\end{tabular}

It can be seen that Variation $3 \mathrm{~b}$ and $4 \mathrm{~b}$ groups of incidents have the highest cost (more than $75 \%$ of overall cost) even though they constitute just $30 \%$ of all incidents and $60 \%$ of all incidents not resolved by the Helpdesk (Service Desk Level 1 support). To reduce cost on VSAT incident support, there is need to review the process of Field Service support that involves working with the NOC.

Table 5. NOC services and activities

\begin{tabular}{|c|c|c|c|c|c|}
\hline & Service & Activities & Manager time & $\begin{array}{l}\text { Operator } \\
\text { time }\end{array}$ & $\begin{array}{l}\text { Agreed time } \\
\quad \text { (Min) }\end{array}$ \\
\hline \multirow{5}{*}{1} & \multirow{5}{*}{ Site Provisioning } & Planning & 5 & 5 & 5 \\
\hline & & Planning with IP request & 10 & 10 & 10 \\
\hline & & $\begin{array}{c}\text { Configuration \& Bandwidth } \\
\text { allocation }\end{array}$ & 15 & 15 & 15 \\
\hline & & $\begin{array}{l}\text { Configuration \& Bandwidth } \\
\text { allocation + Routing }\end{array}$ & 10 & 10 & 10 \\
\hline & & $\begin{array}{c}\text { Configuration \& Bandwidth } \\
\text { allocation + NAT }\end{array}$ & 10 & 10 & 10 \\
\hline \multirow{6}{*}{2} & \multirow{6}{*}{ Site Commissioning } & Signal Level verification & 5 & 10 & 10 \\
\hline & & Cross pole & 5 & 5 & 5 \\
\hline & & Cross pole + Signal optimization & 5 & 5 & 5 \\
\hline & & Cross pole $+\mathrm{CW}$ & 5 & 5 & 5 \\
\hline & & Site registration & 5 & 9 & 9 \\
\hline & & Site setup on management tools & 7 & 11 & 11 \\
\hline \multirow{3}{*}{3} & \multirow{3}{*}{ Level 2 support } & Check Signal strength & 5 & 5 & 5 \\
\hline & & Verify TX error & 5 & 5 & 5 \\
\hline & & Support field engineer & 30 & 30 & 30 \\
\hline \multirow{2}{*}{4} & \multirow{2}{*}{ Level 3 support } & VSAT Hub issue & 60 & 60 & 60 \\
\hline & & Traffic Management & 30 & 30 & 30 \\
\hline 5 & Research and Development & $\begin{array}{l}\text { Support Implementation and test } \\
\text { engineers }\end{array}$ & 120 & 120 & 120 \\
\hline \multirow{3}{*}{6} & \multirow{3}{*}{$\begin{array}{l}\text { Hub infrastructure } \\
\text { management }\end{array}$} & Log Maintenance & 60 & 60 & 60 \\
\hline & & Physical Preventive maintenance & 244 & 244 & 244 \\
\hline & & Logical Preventive maintenance & 180/wk & $120 / \mathrm{wk}$ & 17/day \\
\hline 7 & Database management & Full backup & - & 60 & 60 \\
\hline
\end{tabular}




\begin{tabular}{|c|c|c|c|c|c|}
\hline & & Incremental backup & - & 150 & 150 \\
\hline 8 & $\begin{array}{c}\text { Satellite Space segment } \\
\text { management }\end{array}$ & Monitoring & $60 /$ wk & $60 /$ wk & 9/day \\
\hline 9 & NOC Operations & Reports review & 60/day & 60/day & 60/day \\
\hline 10 & POC support & Setup of test facility & 60 & 120 & 120 \\
\hline 11 & Setup Studio & Video conferencing setup & 30 & 60 & 60 \\
\hline \multirow{2}{*}{12} & \multirow{2}{*}{ Capacity Management } & Capacity Monitoring & 120/day & 120/day & 120/day \\
\hline & & Capacity Planning & $60 / \mathrm{wk}$ & $60 / \mathrm{wk}$ & 12/day \\
\hline \multirow{2}{*}{13} & Hub Operations process & Maintain processes & 30/day & 30/day & 30/day \\
\hline & review & Review processes & $60 /$ month & $60 /$ month & $2 /$ day \\
\hline \multirow{2}{*}{14} & \multirow{2}{*}{ Monitoring and reporting } & Monitoring & 300/day & 300/day & 300/day \\
\hline & & Reporting & 90/day & 90/day & 90/day \\
\hline
\end{tabular}

This same technique can be applied to any of the Incident, Request or Change orders within the IT service units that are under consideration.

\section{Discussion}

The results obtained show that the TDABC model is able to show cost in a structural manner, such that useful information can be obtained to help technical operations managers and supervisors to focus on costly processes, customers or products. The aim of such a focus could be to reduce cost of operations, correctly apply charge back to the business (or customer) and to justify budget requests.

The example used show that by drilling down to different levels of service classification, it is possible to realize what combination of activities will lead to high cost output. The same example can be used to determine where improvements are required in the support process or if it will be more cost effective to outsource that support activity. This is possible because the service management application, CA Service Desk Manager, attribute every request and incident to a customer and a specific site. This way, sites or customers with high cost profiles can be offered a differentiated service (to reduce cost) or have a different support services bill.

There are limitations within the TDABC model developed that limits the level to which it can be applied. The model was developed to provide cost information on the operational aspects of the IT service within the case study organization; other services offered by the IT department (like consulting, training and project management) were not captured as part of this model. The reason for not including these services was that detailed data for past activities and non-cash resource consumption were not maintained by the organization. Another reason was that there were no dedicated team to these services and no clearly defined process and procedure to achieving the tasks within these omitted service areas.

The study set out to develop a TDABC model for an IT Service organization that can be used to understand the cost profile of such an organization to enable meaningful decision making on cost savings. The approach used was to limit the scope to key Service units within the case study organization. These units are primary providers of all the services that the case study organization offers to her customers. To gather information about the activities performed by these units, interviews were done with the service unit managers to get high level activities done to support the final service products the organization offers to her customers. These high level activities were further broken down to show all the actual activity steps and time taken to do them by the operational staff and supervisors.

In the course of developing time equations and testing the TDABC model, the activity list was reorganized and time equation rewritten to make more meaning. The next step was to obtain data about activity performed over a period of 6 months to be used to test the model. The scenario tested showed that the model was able to attribute cost to different variations of the same incident type. Stakeholders agreed that this presented an opportunity to be able to do some cost management actions about the operations around the resolution of that incident type.

Cost management and process improvement are things that will happen when the management and operational managers agree with the method and results of the TDABC model.

The process of working on this study has also shown that information gathering and refining should be a 
continuous process in the development of $\mathrm{ABC}$ models; the better the data is formatted, the easier it is to do the cost modeling. However, to start this kind of project, there should be limited scoping at the initial stage so that there can be results to show to stakeholders quickly. This scope can later be expanded to cover more departments as the interest on TDABC increases.

\section{References}

Bamber, L. S., \& Hughes, K. E. (2001). Activity-Based Costing in the Service Sector: The Buckeye National Bank. Accounting Education, 16(3). http://dx.doi.org/10.2308/iace.2001.16.3.381

Cokins, G. (2001). Activity-Based Cost Management: An Executive's Guide. John Wiley \& Sons Inc.

Huczynski, B. (2007). Organizational Behaviour (6th ed.). Prentice Hall.

Gilbert, S. J. (2007). Adding Time to Activity-Based Costing. Harvard Business School Working Knowledge.

ITIL. (2011). ITIL Home. Retreived from http://www.itil-officialsite.com/

Kaplan, R., \& Anderson, S. (2003). Time-driven activity-based costing. Retrieved from:http://papers.ssrn.com/sol3/papers.cfm?abstract_id $=485443$

Kaplan, R. S., \& Anderson, S. R. (2007). Time-Driven Activity-Based Costing. Boston: Harvard Business School Press.

Kellen, V., \& Wolf, B. (2003). Business Performance Measurement. Information Visualization, 1(312), 1-36. Retrieved from http://www.performance-measurement.net/assets/bluewolf/Article_0502.pdf

Kren, L. (2008). Using Activity-Based management for cost control. Journal of Performance Management, 21(2), 18-28.

LaLonde, B. J., \& Pohlen, T. L. (1996). Issues in supply chain costing. International Journal of Logistics Management, 7(1), 1-12. http://dx.doi.org/10.1108/09574099610805395

Neumann, B. R., Gerlach, J. H., Moldauer, E., Finch, M., \& Olson, C. (2004). Cost management using ABC for IT activities and services. Management Accounting Quarterly, 6(1), 29-40.

Peebles, C., Stewart, C., Voss, B., \& Workman, S. (2001). Measuring Quality, Cost, and Value of IT Services. EDUCAUSE Conference Proceedings, Indianapolis IN.

Reyhanoglu, M. (2004). Activity-Based Costing System Advantages and Disadvantages.

Sanford, R. A. (2011). Impact of Activity-based Costing on Organizational Performance. Proquest, Umi Dissertatio.

Szychta, A. (2010). Time-driven activity-based costing in service industries. Social Sciences/Socialiniai mokslai, 67(1), 49-60.

Turney, P. B. B. (2008). Activity-Based Costing An Emerging Foundation for Performance Management, Cost Technology. Retrieved from http://www.sas.com/resources/whitepaper/wp_5073.pdf

Yin, \& Robert, K. (2009). Case Study Research: Design and Methods (4th ed.). Sage Publications

\section{Appendix}

Table 1. DC services and activities

\begin{tabular}{|c|c|c|c|c|c|}
\hline & Service & Activities & Manager time & Operator time & Agreed time (Min) \\
\hline \multirow[t]{4}{*}{1} & Storage & Plan and implement Windows storage & & 15 & 15 \\
\hline & & Planning Enterprise & & 20 & 20 \\
\hline & & Planning (Unix) & & 5 & 5 \\
\hline & & Scripting (1 time for enterprise) & & 30 & 30 \\
\hline \multirow[t]{6}{*}{2} & Virtualization & Plan and implement Virtual server & & 15 & 15 \\
\hline & & Planning (Enterprise) & & 20 & 20 \\
\hline & & Planning (Unix) & & 5 & 5 \\
\hline & & Scripting ( 1 time for enterprise) & & 30 & 30 \\
\hline & & Provision virtual networks & & 10 & 10 \\
\hline & & Install OS & & 10 & 10 \\
\hline 3 & Backup & Install backup agents (server) & & 30 & 30 \\
\hline
\end{tabular}




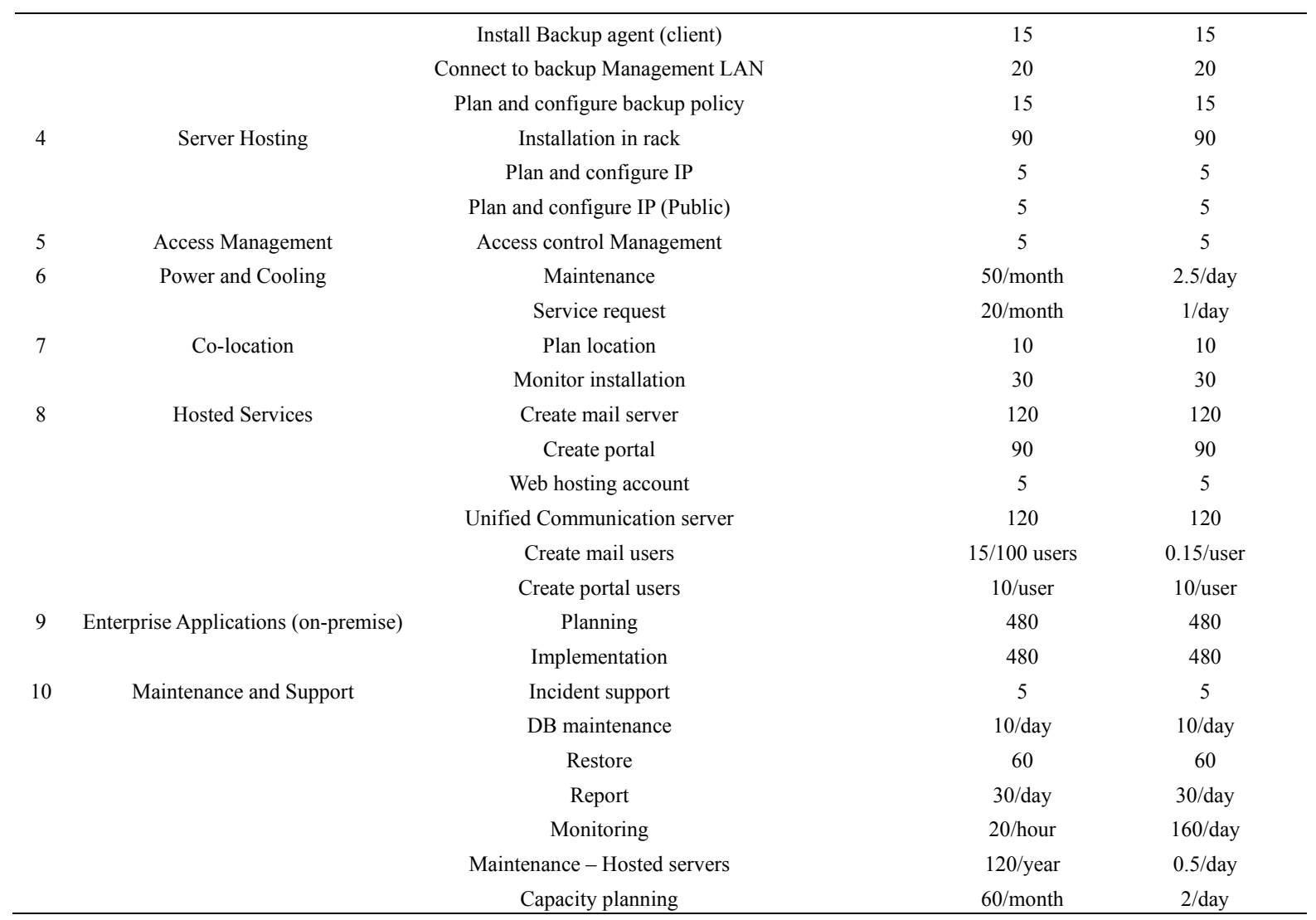

Table 2. Service desk services and activities

\begin{tabular}{|c|c|c|c|c|c|}
\hline & Service & Activities & Manager time & Operator time & $\begin{array}{l}\text { Agreed time } \\
\quad \text { (Min) }\end{array}$ \\
\hline \multirow[t]{8}{*}{1} & Helpdesk services & Call receipt & 1 & 1 & 1 \\
\hline & & Log tickets & 3 & 4 & 4 \\
\hline & & Troubleshooting & 10 & 8 & 10 \\
\hline & & User detail update (new) & 5 & 2 & 3 \\
\hline & & User detail update (existing) & 3 & 2 & 2 \\
\hline & & Survey (per subject) & 15 & 5 & 5 \\
\hline & & IVR Setup & 10 & 10 & 10 \\
\hline & & Reports (per day) & $60 /$ day & $50 /$ day & $50 /$ day \\
\hline \multirow[t]{4}{*}{2} & Incident Management & Daily Incident review & 120 & 200 & 200 \\
\hline & & Escalation & 20 & 25 & 25 \\
\hline & & Incident Closure & 5 & 5 & 5 \\
\hline & & Reports (per day) & 30/day & $15 /$ day & $15 /$ day \\
\hline \multirow[t]{4}{*}{3} & Change Management & Review Change document & 7 & 12 & 10 \\
\hline & & Process Change approval & 4 & 4 & 4 \\
\hline & & Review Change reports & 5 & 6 & 6 \\
\hline & & Close change ticket & 3 & 2 & 2 \\
\hline 4 & $\begin{array}{l}\text { Process and Service review } \\
\text { meetings }\end{array}$ & Process and Service review meetings & $120 /$ week & 120/week & $24 /$ day \\
\hline
\end{tabular}


Table 3. Field services and activities

\begin{tabular}{|c|c|c|c|c|c|}
\hline & Service & Activities & Manager time & $\begin{array}{c}\text { Operator } \\
\text { time }\end{array}$ & $\begin{array}{c}\text { Agreed time } \\
\text { (Min) }\end{array}$ \\
\hline \multirow{4}{*}{1} & \multirow{4}{*}{ VSAT support } & VSAT relocation/new installation & 1-3days & 3days & 960 \\
\hline & & Re-alignment & 2hours & $3 \mathrm{hrs}$ & 180 \\
\hline & & Device Replacement & 1hour & $3 \mathrm{hrs}$ & 60 \\
\hline & & Wireless installation & 1hour & $30 \mathrm{~min}$ & 30 \\
\hline \multirow{4}{*}{2} & \multirow{4}{*}{ Fibre Support } & Checking connectivity & 10minutes & $25 \mathrm{~min}$ & 10 \\
\hline & & Checking traffic condition & $5-10$ minutes & $10 \mathrm{~min}$ & 10 \\
\hline & & LAN Audit & 2hours & $1 \mathrm{hr}$ & 90 \\
\hline & & Voltage Reading & 5minutes & $5 \min$ & 5 \\
\hline \multirow{3}{*}{3} & \multirow{3}{*}{ Radio Support } & Checking link status & 5minutes & $10 \mathrm{~min}$ & 10 \\
\hline & & Checking frequency & 5minutes & $20 \mathrm{~min}$ & 10 \\
\hline & & Device replacement & 2-3hours & $3 \mathrm{hrs}$ & 180 \\
\hline \multirow{4}{*}{4} & \multirow{4}{*}{ Site Survey } & Radio- line of sight & 1hour & $1 \mathrm{hr}$ & 60 \\
\hline & & Fibre- cable path & 3hours & $4 \mathrm{hrs}$ & 180 \\
\hline & & LAN survey & 1hour & $1 \mathrm{hr}$ & 60 \\
\hline & & VSAT survey & 1hour & $1 \mathrm{hr}$ & 60 \\
\hline \multirow{2}{*}{5} & \multirow{2}{*}{ LAN Support } & Using fluke analyser & 1 day & $3 \mathrm{hrs}$ & 360 \\
\hline & & LAN extension & 2days & 1day & 480 \\
\hline 6 & $\begin{array}{l}\text { Third party support } \\
\text { Management }\end{array}$ & Supervision of vendors & & 1 day & 480 \\
\hline \multirow{2}{*}{7} & \multirow{2}{*}{ Power Systems support } & Power extension & 1day & & 480 \\
\hline & & Earth Protection & 2days & 1day & 480 \\
\hline
\end{tabular}

Table 4. NOC time equation

\begin{tabular}{|c|c|c|c|c|}
\hline & Service & Activities & Time & Time Equations \\
\hline \multirow[t]{5}{*}{1} & Site Provisioning & Planning & 5 & $5+10\{$ if with IP $\}+15\{$ Bandwidth allocation $\}+$ \\
\hline & & Planning with IP request & 10 & $10\{$ Routing $\}+10\{\mathrm{NAT}\}$ \\
\hline & & $\begin{array}{l}\text { Configuration \& Bandwidth } \\
\text { allocation }\end{array}$ & 15 & \\
\hline & & $\begin{array}{l}\text { Configuration \& Bandwidth } \\
\text { allocation + Routing }\end{array}$ & 10 & \\
\hline & & $\begin{array}{l}\text { Configuration \& Bandwidth } \\
\text { allocation + NAT }\end{array}$ & 10 & \\
\hline \multirow[t]{6}{*}{2} & Site Commissioning & Signal Level verification & 10 & $10+5\{$ if Cross pole $\}+5\{$ if optimization $\}+5\{$ if \\
\hline & & Cross pole & 5 & $\mathrm{CW}\}+9\{$ if site reg. $\}+11$ if Mgt. tool $\}$ \\
\hline & & $\begin{array}{l}\text { Cross pole }+ \text { Signal } \\
\text { optimization }\end{array}$ & 5 & \\
\hline & & Cross pole $+\mathrm{CW}$ & 5 & \\
\hline & & Site registration & 9 & \\
\hline & & Site setup on management tools & 11 & \\
\hline \multirow[t]{3}{*}{3} & Level 2 support & Check Signal strength & 5 & $5\{$ if check signal $\}+5\{$ if $T X$ error $\}+30\{$ if support \\
\hline & & Verify TX error & 5 & field engr.\} \\
\hline & & Support field engineer & 30 & \\
\hline \multirow[t]{2}{*}{4} & Level 3 support & VSAT Hub issue & 60 & $60+30\{$ if traffic mgt. issue $\}$ \\
\hline & & Traffic Management & 30 & \\
\hline 5 & $\begin{array}{l}\text { Research } \\
\text { Development }\end{array}$ & $\begin{array}{l}\text { Support Implementation and } \\
\text { test engineers }\end{array}$ & 120 & 120 \\
\hline \multirow[t]{3}{*}{6} & Hub infrastructure & Log Maintenance & 60 & $60+244\{$ if physical maint. $\}+17 /$ day \\
\hline & management & $\begin{array}{ll}\text { Physical } & \text { Preventive } \\
\text { maintenance } & \end{array}$ & 244 & \\
\hline & & Logical Preventive maintenance & 17/day & \\
\hline
\end{tabular}




\begin{tabular}{|c|c|c|c|c|}
\hline \multirow[t]{2}{*}{7} & \multirow[t]{2}{*}{ Database management } & Full backup & 60 & $60+150\{$ if incremental $\}$ \\
\hline & & Incremental backup & 150 & \\
\hline 8 & $\begin{array}{l}\text { Satellite Space } \\
\text { segment management }\end{array}$ & Monitoring & 9/day & $9 /$ day \\
\hline 9 & NOC Operations & Reports review & $60 /$ day & $60 /$ day \\
\hline 10 & POC support & Setup of test facility & 120 & 120 \\
\hline 11 & Setup Studio & Video conferencing setup & 60 & 60 \\
\hline \multirow[t]{2}{*}{12} & Capacity Management & Capacity Monitoring & $120 /$ day & $(120+12) /$ day \\
\hline & & Capacity Planning & $12 /$ day & \\
\hline \multirow[t]{2}{*}{13} & Operations & Maintain processes & $30 /$ day & $(30+2) /$ day \\
\hline & process review & Review processes & $2 /$ day & \\
\hline \multirow[t]{2}{*}{14} & Monitoring & Monitoring & $300 /$ day & $(300+90) /$ day \\
\hline & reporting & Reporting & 90/day & \\
\hline
\end{tabular}

Table 5. NOC business time equation

\begin{tabular}{ll}
\hline Service & Time Equation \\
\hline NOC Business services & {$[9\{$ Space segment $\}+60\{$ NOC operations $\}+132\{$ Capacity $\}+32\{$ Operation review $\}+390\{$ Monitoring $\}+$} \\
& $17\{$ Logical maint. $\}]+120\{$ if $R \& D\}+60\{$ if log maint. $\}+244\{$ if physical maint. $\}+60\{$ if full DB backup $\}$ \\
& $+150\{$ if incr. backup $\}+120\{$ if POC $\}+60\{$ if Setup studio $\}$ \\
\hline
\end{tabular}

Table 6. Data centre time equations

\begin{tabular}{|c|c|c|c|c|}
\hline & Service & Activities & Time & Time Equations \\
\hline \multirow{4}{*}{1} & \multirow{4}{*}{ Storage } & $\begin{array}{c}\text { Plan and implement Windows } \\
\text { storage }\end{array}$ & 15 & \multirow{4}{*}{$15+20\{$ if enterprise $\}+5\{$ if unix $\}+30\{$ if scripting $\}$} \\
\hline & & Planning Enterprise & 20 & \\
\hline & & Planning (Unix) & 5 & \\
\hline & & $\begin{array}{l}\text { Scripting (1 time for } \\
\text { enterprise) }\end{array}$ & 30 & \\
\hline \multirow{6}{*}{2} & \multirow{6}{*}{ Virtualization } & $\begin{array}{c}\text { Plan and implement Virtual } \\
\text { server }\end{array}$ & 15 & \multirow{6}{*}{$\begin{array}{c}15+20\{\text { if enterprise }\}+5\{\text { if unix }\}+30\{\text { if scripting }\}+ \\
10\{\text { if virtual network }\}+10\{\text { if OS }\}\end{array}$} \\
\hline & & Planning (Enterprise) & 20 & \\
\hline & & Planning (Unix) & 5 & \\
\hline & & $\begin{array}{l}\text { Scripting (1 time for } \\
\text { enterprise) }\end{array}$ & 30 & \\
\hline & & Provision virtual networks & 10 & \\
\hline & & Install OS & 10 & \\
\hline \multirow{4}{*}{3} & \multirow{4}{*}{ Backup } & Install backup agents (server) & 30 & \multirow{4}{*}{$\begin{array}{c}30\{\text { backup agent-if server }\}+15 \text { \{backup agent- if client }\}+ \\
20\{\text { if connect mgt. LAN }\}+15\{\text { if backup policy }\}\end{array}$} \\
\hline & & Install Backup agent (client) & 15 & \\
\hline & & $\begin{array}{l}\text { Connect to backup } \\
\text { Management LAN }\end{array}$ & 20 & \\
\hline & & $\begin{array}{l}\text { Plan and configure backup } \\
\text { policy }\end{array}$ & 15 & \\
\hline \multirow{3}{*}{4} & \multirow{3}{*}{ Server Hosting } & Installation in rack & 90 & \multirow{3}{*}{$90+5\{$ if Private IP $\}+5\{$ if Public $\}$} \\
\hline & & Plan and configure IP & 5 & \\
\hline & & Plan and configure IP (Public) & 5 & \\
\hline \multirow{5}{*}{5} & & Create mail server & 120 & \multirow{5}{*}{$\begin{array}{c}120+90\{\text { if portal }\}+5\{\text { if Web hosting }\}+20\{\text { if unified } \\
\text { comm. server }\}+0.15 \text { per mail user }\}+10\{\text { per portal user }\}\end{array}$} \\
\hline & & Create portal & 90 & \\
\hline & Hosted Services & Web hosting account & 5 & \\
\hline & & $\begin{array}{l}\text { Unified Communication } \\
\text { server }\end{array}$ & 120 & \\
\hline & & Create mail users & $0.15 /$ user & \\
\hline
\end{tabular}




\begin{tabular}{|c|c|c|c|c|}
\hline \multirow{3}{*}{6} & \multirow{3}{*}{$\begin{array}{l}\text { Enterprise Applications } \\
\quad \text { (on-premise) }\end{array}$} & Create portal users & $10 /$ user & \multirow{3}{*}{$480+480\{$ if implementing $\}$} \\
\hline & & Planning & 480 & \\
\hline & & Implementation & 480 & \\
\hline 7 & Access Management & Access control Management & 5 & $5\{$ if access control $\}$ \\
\hline 8 & Power and Cooling & Maintenance & $2.5 /$ day & \multirow{2}{*}{$(2.5\{$ if maint. $\}+1\{$ if service request $\}) /$ day } \\
\hline & & Service request & $1 /$ day & \\
\hline \multirow[t]{2}{*}{9} & \multirow[t]{2}{*}{ Co-location } & Plan location & 10 & \multirow[t]{2}{*}{$10+30\{$ if supervision $\}$} \\
\hline & & Monitor installation & 30 & \\
\hline \multirow{7}{*}{10} & \multirow{7}{*}{$\begin{array}{l}\text { Maintenance } \\
\text { Support }\end{array}$} & Incident support & 5 & \multirow{7}{*}{$\begin{aligned} & 5+60\{\text { if DB restore }\}+(10\{\text { DB maint }\}+30\{\text { Report }\}+ \\
& 160\{\text { monitoring }\}+ 0.5\{\text { hosted server maint. }\}+2\{\text { Cap. } \\
&\text { Planning }\}) / \text { day }\end{aligned}$} \\
\hline & & DB maintenance & 10/day & \\
\hline & & Restore & 60 & \\
\hline & & Report & $30 /$ day & \\
\hline & & Monitoring & $160 /$ day & \\
\hline & & Maintenance - Hosted servers & $0.5 /$ day & \\
\hline & & Capacity planning & $2 /$ day & \\
\hline
\end{tabular}

Table 7. Data centre business time equation

\begin{tabular}{ll}
\hline Service & Time Equation \\
\hline DC Business Services & $\begin{array}{l}{[3.5\{\text { Power and Cooling }\}+10\{\text { DB Maint. }\}+30\{\text { Report }\}+160\{\text { Monitoring }\}+0.5\{\text { Server maint. }\}+2\{\text { Capacity }} \\
\text { plan }\}] / \text { day }+5\{\text { if access control }\}+40\{\text { if co-location }\}+5\{\text { per incident support }\}+60\{\text { if DB restore }\}\end{array}$ \\
\hline
\end{tabular}

Table 8 . Service desk time equations

\begin{tabular}{|c|c|c|c|c|}
\hline & Service & Activities & Time & Time Equations \\
\hline \multirow[t]{7}{*}{1} & \multirow[t]{7}{*}{ Helpdesk services } & Call receipt & 1 & \multirow{7}{*}{$\begin{array}{l}1\{\text { if Call receipt }\}+4\{\text { if logging }\}+10\{\text { if troubleshoot }\} \\
+3\{\text { new user detail }\}+2\{\text { if update existing user }\}+5\{\text { if } \\
\text { survey }\}+5\{\text { if Close }\}\end{array}$} \\
\hline & & Log tickets & 4 & \\
\hline & & Troubleshooting & 10 & \\
\hline & & User detail update (new) & 3 & \\
\hline & & User detail update (existing) & 2 & \\
\hline & & Survey (per subject) & 5 & \\
\hline & & Incident Closure & 5 & \\
\hline \multirow[t]{4}{*}{2} & \multirow[t]{4}{*}{ Change Management } & Review Change document & 10 & \multirow[t]{4}{*}{$10+4\{$ if approval $\}+6\{$ if reports $\}+2\{$ if close $\}$} \\
\hline & & Process Change approval & 4 & \\
\hline & & Review Change reports & 6 & \\
\hline & & Close change ticket & 2 & \\
\hline 3 & $\begin{array}{l}\text { Process and Service } \\
\text { review meetings }\end{array}$ & $\begin{array}{l}\text { Process and Service review } \\
\text { meetings }\end{array}$ & $24 /$ day & 24 \{meetings\} \\
\hline \multirow[t]{4}{*}{4} & \multirow[t]{4}{*}{ Incident Management } & Daily Incident review & 200 & \multirow{4}{*}{$\begin{array}{l}200\{\text { incident review }\}+25\{\text { if escalation }\}+65 \text { daily } \\
\text { report }\}+10\{\text { if IVR setup }\}\end{array}$} \\
\hline & & Escalation & 25 & \\
\hline & & Reports (per day) & $65 /$ day & \\
\hline & & IVR Setup & 10 & \\
\hline
\end{tabular}

Table 9. Service desk business equation 
Table 10. Field services time equations

\begin{tabular}{|c|c|c|c|c|}
\hline & Service & Activities & Time & Time Equations \\
\hline \multirow[t]{4}{*}{1} & VSAT support & $\begin{array}{ll}\text { VSAT } & \text { relocation/new } \\
\text { installation } & \end{array}$ & 960 & $\begin{array}{l}960\{\text { if installation }\}+180\{\text { if alignment }\}+60\{\text { if replacement }\}+ \\
30\{\text { if wireless }\}\end{array}$ \\
\hline & & Re-alignment & 180 & \\
\hline & & Device Replacement & 60 & \\
\hline & & Wireless installation & 30 & \\
\hline \multirow[t]{4}{*}{2} & Fibre Support & Checking connectivity & 10 & $10\{$ if check connectivity $\}+10\{$ if check traffic $\}+90\{$ if LAN \\
\hline & & Checking traffic condition & 10 & audit $\}+5\{$ if voltage $\}$ \\
\hline & & LAN Audit & 90 & \\
\hline & & Voltage Reading & 5 & \\
\hline \multirow[t]{3}{*}{3} & Radio Support & Checking link status & 10 & $10\{$ if check link $\}+10\{$ if check freq. $\}+180\{$ if replace device $\}$ \\
\hline & & Checking frequency & 10 & \\
\hline & & Device replacement & 180 & \\
\hline \multirow[t]{4}{*}{4} & Site Survey & Radio- line of sight & 60 & $60\{$ if radio $\}+180\{$ if fibre $\}+60\{$ if LAN $\}+60\{$ if VSAT $\}$ \\
\hline & & Fibre- cable path & 180 & \\
\hline & & LAN survey & 60 & \\
\hline & & VSAT survey & 60 & \\
\hline \multirow[t]{2}{*}{5} & LAN Support & Using fluke analyser & 360 & $360\{$ if fluke analysis $\}+480\{$ if LAN extension $\}$ \\
\hline & & LAN extension & 480 & \\
\hline \multirow[t]{2}{*}{6} & Third party support & Supervision of vendors & 480 & $480\{$ if vendor supervision $\}$ \\
\hline & Management & & & \\
\hline \multirow[t]{2}{*}{7} & Systems & Power extension & 480 & $480\{$ if extension $\}+480\{$ if earth protection $\}$ \\
\hline & support & Earth Protection & 480 & \\
\hline
\end{tabular}

\section{Copyrights}

Copyright for this article is retained by the author(s), with first publication rights granted to the journal.

This is an open-access article distributed under the terms and conditions of the Creative Commons Attribution license (http://creativecommons.org/licenses/by/3.0/). 